OPEN ACCESS

Edited by:

Anna Fogdell-Hahn, Karolinska Institutet (KI), Sweden

Reviewed by:

Sudarshini Ramanathan, The University of Sydney, Australia Erdem Tüzün

Istanbul University, Turkey

*Correspondence:

Huiqin Xu

xuhuiqin@wmu.edu.cn

†These authors have contributed equally to this work

Specialty section: This article was submitted to

Multiple Sclerosis and

Neuroimmunology, a section of the journal

Frontiers in Neurology

Received: 09 September 2020 Accepted: 31 March 2021

Published: 14 May 2021

Citation:

Ding S, Gong J, Lin J, Wang Y, Hua Y, Li X, Du Y, Xia N, Zhu Z, Wang $X$,

Zheng $R$ and $X u H$ (2021) Validation of Predictive Models for Autoimmune Encephalitis-Related Antibodies to Cell-Surface Proteins Expressed in Neurons: A Retrospective Study Based in a Hospital. Front. Neurol. 12:601761. doi: 10.3389/fneur.2021.601761

\section{Validation of Predictive Models for Autoimmune Encephalitis-Related Antibodies to Cell-Surface Proteins Expressed in Neurons: A Retrospective Study Based in a Hospital}

Siqi Ding ${ }^{1 \dagger}$, Jiaoni Gong ${ }^{1 \dagger}$, Jiahe Lin ${ }^{1}$, Yi Wang ${ }^{2}$, Yingjie Hua ${ }^{1}$, Xueying $\mathrm{Li}^{1}$, Yanru Du ${ }^{1}$, Niange Xia ${ }^{1}$, Zhenguo Zhu ${ }^{1}$, Xinshi Wang ${ }^{1}$, Rongyuan Zheng ${ }^{1}$ and Huiqin $X^{1 *}$

${ }^{1}$ Department of Neurology, The First Affiliated Hospital of Wenzhou Medical, University, Wenzhou, China, ${ }^{2}$ Department of Preventive Medicine, School of Public Health and Management, Wenzhou Medical University, Wenzhou, China

Objective: Autoimmune encephalitis (AE) is a severe but treatable autoimmune disorder that is diagnosed by antibody (Ab) testing. However, it is unrealistic to obtain an early diagnosis in some areas since the Ab status cannot be immediately determined due to time and technology restrictions. In our study, we aimed to validate the Antibody Prevalence in Epilepsy and Encephalopathy $\left(\mathrm{APE}^{2}\right)$ score among patients diagnosed with possible AE as a predictive model to screen AE patients with antibodies to cell-surface proteins expressed in neurons.

Methods: A total of 180 inpatients were recruited, and antibodies were detected through serological and/or cerebrospinal fluid (CSF) evaluations. The $\mathrm{APE}^{2}$ score was used to validate the predictive models of $\mathrm{AE}$ with autoantibodies.

Results: The mean APE ${ }^{2}$ score in the Ab-positive cases was 7.25, whereas the mean $\mathrm{APE}^{2}$ score in the Ab-negative cases was $3.18(P<0.001)$. The $\mathrm{APE}^{2}$ score had a receiver operating characteristic (ROC) area under the curve of $0.924[P<0.0001,95 \%$ confidence interval $(\mathrm{Cl})=0.875-0.973]$. With a cutoff score of 5 , the $\mathrm{APE}^{2}$ score had the best psychometric properties, with a sensitivity of 0.875 and a specificity of 0.791 .

Conclusion: The $\mathrm{APE}^{2}$ score is a predictive model for $\mathrm{AE}$ with autoantibodies to cell-surface proteins expressed in neurons and was validated and shown to have high sensitivity and specificity in our study. We suggest that such a model should be used in patients with a suspected diagnosis of $A E$, which could increase the detection rate of Abs, reduce testing costs, and help patients to benefit from treatment quickly.

Keywords: autoimmune encephalitis, antibody, antibody prevalence in epilepsy and encephalopathy (APE ${ }^{2}$ score), $^{2}$ predictive model, validation 


\section{INTRODUCTION}

Autoimmune encephalitis (AE) is an immune-mediated neurological disorder characterized by rapidly progressive central nervous system (CNS) symptoms that is associated with specific autoantibodies targeting cell-surface neuronal antigens (1). AE is classified into different subtypes according to the neuronal antigens targeted by the autoantibodies found in the serum and/or cerebrospinal fluid (CSF) of patients, each of which has different clinical characteristics and outcomes $(1,2)$. The identified forms of AE might be associated with antibodies (Abs) against intracellular antigens, synaptic receptors, ion channels, or cell-surface proteins, according to the location of these specific autoantibodies (3).

As more related cases have been identified in the past 10 years, there has been increasing interest in the pathogenesis and clinical features of $\mathrm{AE}$, especially in patients with Abs to cell-surface proteins expressed in neurons, including antibodies against synaptic receptors and antibodies targeting ion channels and cell-surface proteins, who have an effective response to immunosuppressive therapies and who respond well to immunosuppressive therapies (4). Abs to N-methyl-D-aspartate receptor (NMDAR), gamma-aminobutyric acid A receptor (GABAAR), gamma-aminobutyric acid B receptor (GABABR), alpha-amino-3-hydroxy-5-methyl-4-isoxazolepropionic acid receptor (AMPAR), metabotropic glutamate receptor 5 (mGluR5), dopamine 2 receptor, leucine-rich gliomainactivated 1 (LGI1), contactin-associated protein-like 2 (Caspr2), and dipeptidyl-peptidase-like protein 6 (DPPX) were identified in patients and were associated with various clinical manifestations (5).

The current diagnostic criteria for $\mathrm{AE}$ depend heavily on $\mathrm{Ab}$ testing and responses to immunotherapy (6). However, the identification of the different forms of Abs involved with $\mathrm{AE}$ is a complicated process. The diagnosis of AE should be suspected based on $\mathrm{Ab}$ identification, as well as combination of disease signs and symptoms (3). In addition, some patients with $\mathrm{AE}$ may not respond to immunotherapy or may require intensive and long-term treatment, which is unavailable in most health care systems unless a diagnosis has been previously established (2). However, rapid access to gold standard diagnostic cellbased assays is not universally available, especially in some areas where medical conditions are limited. An Ab prediction model that is not based on $\mathrm{Ab}$ detection not only is helpful for early diagnosis but also can save medical resources and reduce the economic burden of patients. These issues prompted researchers to explore methods for the early diagnosis of $\mathrm{AE}$ and to establish predictive models for the detection of autoantibodies based on the clinical presentation and initial neurologic evaluations prior to $\mathrm{Ab}$ testing.

Recently, an Antibody Prevalence in Epilepsy and Encephalopathy $\left(\mathrm{APE}^{2}\right)$ score was described as a model for predicting the detection of neural-specific autoantibodies based on clinical characteristics; this model was validated and had high sensitivity and specificity for identifying patients with cognitive decline (7-9). AE usually presents with the subacute onset of memory deficits or an altered mental status, which may or may not be accompanied by other symptoms (2). Therefore, we aimed to validate the $\mathrm{APE}^{2}$ scoring system as a predictive model to screen $\mathrm{AE}$ patients with antibodies to cell-surface proteins expressed in neurons among patients diagnosed with possible AE.

\section{METHODS}

\section{Subjects}

We conducted a retrospective review of inpatients diagnosed with possible AE between June 2014 and June 2019 at the First Affiliated Hospital of Wenzhou Medical University, China. The levels of $\mathrm{AE}$ autoantibodies of every inpatient were detected through serological and/or CSF evaluations. Patients were included in the study based on the following criteria: (1) onset of working memory deficits (short-term memory loss), altered mental status, or psychiatric symptoms; (2) at least one of the following: new focal CNS findings, seizures not explained by a previously known seizure disorder, CSF pleocytosis [white blood cell (WBC) count of more than 5 cells per $\mathrm{mm}$ ], and magnetic resonance imaging (MRI) features suggestive of encephalitis; and (3) reasonable exclusion of alternative causes. Patients with incomplete medical record information were excluded.

\section{Ab Evaluations}

All serum and CSF specimens were screened by standardized indirect immunofluorescence assays (IFAs) and cell-based assays (CBAs) using human embryonic kidney (HEK) 293 cells transfected with appropriate expression plasmids to confirm IgGs specific for NMDAR, AMPA1, AMPA2, LGI1, CASPR2, GABABR, and DPPX. The initial dilution titers of CSF and serum were $1: 1$ and 1:10, respectively.

\section{Data Collection}

Data were gathered from each patient, which included basic demographic information (age and sex), the duration of symptoms before hospitalization, the presence and type of seizures, status epilepticus, mental disorders, sleep disorders, headache, laboratory data, and CSF results (protein, WBCs, glucose, and chloride), MRI, anticardiolipin antibody (ACA), antinuclear antibody (ANA), treatment, intensive care unit (ICU) admission, the need for mechanical ventilation, and the prognosis during hospitalization. The $\mathrm{APE}^{2}$ score of each inpatient was evaluated by a neurologist based on the clinical manifestations, and the neurologists were blinded to the actual results of $\mathrm{Ab}$ evaluations.

\section{$\mathrm{APE}^{2}$ Score}

The initial version of the Antibody Prevalence in Epilepsy (APE) score was established by Dubey as a model to predict the detection of neural Abs in autoimmune epilepsy patients based on clinical manifestations and initial neurologic evaluations (7). An APE score of $\geq 4$ had a sensitivity and specificity of 82.6 and $82.0 \%$, respectively, and can be used as a tool for identifying patients for $\mathrm{Ab}$ testing (7). After three modifications, the $\mathrm{APE}^{2}$ scoring system has a higher specificity for the prediction of neural autoantibody positivity (from 78 to $84 \%$ ) among patients 
with epilepsy, without a loss in sensitivity (98\%) (9). The determination of the $\mathrm{APE}^{2}$ score in patients with encephalopathy or cognitive decline to predict AE-related Ab positivity showed that an $\mathrm{APE}^{2}$ score $\geq 4$ was $99 \%$ sensitive and $93 \%$ specific for neural-specific Abs (8).

\section{Statistical Analysis}

The data were analyzed using the Statistical Package for the Social Sciences (SPSS version 20.0; SPSS Inc., Chicago, IL, USA). Sociodemographic characteristics and clinical variables are presented as counts, frequency (\%), means, and standard deviations. Categorical variables were compared using chi-square tests or Fisher's exact tests. Interval variables were performed using Mann-Whitney $U$-tests. The threshold for statistical significance was set at $P<0.05$ (two-tailed). The odds ratio (OR) and 95\% confidence intervals (CIs) were used to quantify the strength of the associations. Receiver operating characteristic (ROC) curve analysis was performed to assess the sensitivity, specificity, Youden index, and positive and negative predictive values of the $\mathrm{APE}^{2}$ score at different cutoff scores.

\section{RESULTS}

Serum, CSF, or both were collected from 238 patients at the onset of the study for the detection of AE-related $\mathrm{Ab}$ testing. Thirty-five patients were excluded due to an indefinite diagnosis of encephalitis, whereas 23 patients were excluded due to incomplete records and insufficient clinical data. The final study group consisted of 180 inpatients, among whom 102 patients underwent simultaneous serum and CSF examinations, 38 patients underwent only serum examinations, and 40 patients underwent only CSF examinations. AE-related antibodies in the serum/CSF were detected in 32 of the 180 inpatients, including $\operatorname{NMDAR}(n=23)$, LGI1 $(n=3)$, GABABR $(n=$ $3)$, CASPR2 $(n=2)$, and AMPA1 $(n=1)$, which were in accordance with the diagnostic standards of AE. A large number of patients with AE have no well-defined syndrome. According to three types of specific syndromes associated with AE (5), there were anti-NMDAR encephalitis $(n=23)$, limbic encephalitis $(n=7)$, and Morvan's syndrome $(n=2)$. Among these 32 patients, $28(87.5 \%)$ had new-onset seizures, and $28(87.5 \%)$ had mental status changes. Regarding prognosis, 23 (71.9\%) patients recovered well, 7 (21.9\%) patients did not respond to treatment, and $2(6.3 \%)$ patients were discharged after the deterioration of their condition. Table 1 shows the detailed information of the $\mathrm{Ab}$-positive group and the Ab-negative group, such as the basic demographic information, clinical features, laboratory data, treatment, and prognosis.

In Table 2, we compared the differences in the $\mathrm{APE}^{2}$ score between the two groups and evaluated the associations with clinical characteristics. According to the results of univariate analysis, the following items were associated with the Abpositive group: neuropsychiatric changes $(P<0.001, \mathrm{OR}=$ 5.930), autonomic dysfunction $(P<0.001, \mathrm{OR}=11.308)$, viral prodrome $(P<0.001$, OR $=3.655)$, faciobrachial dystonic seizures $(P<0.001$, OR $=6.692)$, facial dyskinesias $(P=$ 0.016$, OR $=2.964)$, refractory epilepsy $(P<0.001$, OR $=$
7.367), and encephalitis and a cancer diagnosis within 5 years of encephalopathy or cognitive dysfunction $(P=0.018$, OR $=4.552)$. Conversely, there were no associations between $\mathrm{Ab}$ positivity and subacute encephalopathy/new-onset epilepsy $(P=$ $0.113)$, CSF inflammatory changes $(P=0.564)$, or MRI changes $(P=0.702)$. The mean $\mathrm{APE}^{2}$ scores (Table 1$)$ were 7.25 in the $\mathrm{Ab}$-positive group and 3.18 in the Ab-negative group $(P<0.001)$.

The area under the ROC of the $\mathrm{APE}^{2}$ score was $0.924(P<$ $0.0001,95 \% \mathrm{CI}=0.875-0.973$ ) (Figure 1). As a model to predict $\mathrm{Ab}$-positive $\mathrm{AE}$, an $\mathrm{APE}^{2}$ score $\geq 5$ had a sensitivity of 0.875 , a specificity of 0.791 , and a Youden index of 0.666 (Table 3). The Hosmer-Lemeshow test $P$-value was 0.827 in our study.

We also examined the score distribution of each patient in Figure 2 to perform further comparisons. NMDAR Ab cases were compared separately from other Ab cases (such as LGI1, GABABR, CASPR2, and AMPA1) in the 32 patients with positive Abs, and the mean $\mathrm{APE}^{2}$ scores were 7.74 and 6, respectively $(P=0.058)$.

\section{DISCUSSION}

This retrospective study was based in a hospital. Among the patients diagnosed with possible AE, $17.8 \%$ had AE-related Abs, which were not present at a low rate. This study suggests that AE among hospitalized patients with encephalopathy is not wellrecognized. As a prediction model for $\mathrm{AE}$, the $\mathrm{APE}^{2}$ scoring system has high sensitivity and specificity, which makes this prediction model more widely used.

The clinical manifestations of $\mathrm{AE}$ varied. A large number of patients with $\mathrm{AE}$ do not present with a defined syndrome (10). Autoantibody testing is the most clear and important way to determine the diagnosis of these different conditions, and we can define comorbidities, tumor associations, and prognosis according to these testing results (2). However, immunemediated limbic encephalitis can occur without detectable autoantibodies, which means that the absence of autoantibodies does not exclude the possibility of AE. In our study, a patient with abnormal behavior and apathy as initial symptoms responded well to immunotherapy. However, the previous two autoimmunity antibodies tested in the CSF were negative, and NMDAR antibodies were found in the third test. Hence, more methods are needed to screen AE patients with antibodies to cellsurface proteins expressed in neurons in clinical practice. As a predictive model with high sensitivity and specificity, the $\mathrm{APE}^{2}$ score is well-defined, easily measured, routinely available, and can be used at the bedside. Therefore, the use of the $\mathrm{APE}^{2}$ score during diagnosis to screen out suspicious patients is beneficial.

The inclusion criteria used in our study were based on Graus's criteria. However, the duration of symptoms before hospitalization was not strictly defined. A subacute disease duration (rapid progression of $<3$ months) is important to the diagnosis of possible AE. When we reviewed the patients' histories, we found that some patients first presented with a single neurological or psychiatric symptom and developed other symptoms weeks or even months after the onset, which may have led to delays in seeking medical attention. Patients whose disease 
TABLE 1 | Clinical characteristics of patients in the study.

\begin{tabular}{|c|c|c|c|}
\hline Variables & $\begin{array}{l}\text { Antibody-positive } \\
\text { cases }(n=32)\end{array}$ & $\begin{array}{l}\text { Antibody-negative } \\
\text { cases }(n=148)\end{array}$ & $P$-value \\
\hline Median age, years (range) & $41.09(14-78)$ & $48.93(15-87)$ & 0.035 \\
\hline Female $N(\%)$ & $12(37.5)$ & $56(37.8)$ & 0.971 \\
\hline Median $\mathrm{APE}^{2}$ score & 7.25 & 3.18 & 0.000 \\
\hline New-onset seizures (\%) & $28(87.5)$ & $79(53.4)$ & 0.000 \\
\hline Duration of symptoms before hospitalization (weeks) & & & 0.293 \\
\hline $1-6$ & $31(96.9)$ & $125(84.5)$ & \\
\hline $6-12$ & $1(3.1)$ & $7(4.7)$ & \\
\hline $12-24$ & 0 & $3(2.0)$ & \\
\hline$>24$ & 0 & $13(8.8)$ & \\
\hline Type of seizure (\%) & & & 0.000 \\
\hline No & $4(12.5)$ & $69(46.6)$ & \\
\hline FES & $4(12.5)$ & $20(13.5)$ & \\
\hline GES & $12(37.5)$ & $41(27.7)$ & \\
\hline 2nd GES & $12(37.5)$ & $18(12.1)$ & \\
\hline Status epilepticus (\%) & $11(34.4)$ & $10(6.8)$ & 0.000 \\
\hline Mental status changes (\%) & $28(87.5)$ & $108(73)$ & 0.083 \\
\hline Sleep disorder diagnosis (\%) & $4(12.5)$ & $18(12.2)$ & 1.000 \\
\hline Headache (\%) & $8(25)$ & $49(33.1)$ & 0.371 \\
\hline CSF protein > 50 mg/dl (\%) & $6(18.75)$ & $87(58.8)$ & 0.000 \\
\hline CSF cell count $>5$ cells/dl (\%) & $31(96.875)$ & $128(86.5)$ & 0.175 \\
\hline CSF glucose & $3.741(0.7374)$ & $3.941(1.3785)$ & 0.776 \\
\hline CSF chloride & $121.75(5.798)$ & $122.57(6.842)$ & 0.716 \\
\hline MRI (T2/FLAIR hyperintensity) & & & 1.000 \\
\hline Normal & $17(53.1)$ & $86(58.1)$ & \\
\hline One or both medial temporal lobes & $4(12.5)$ & $8(5.4)$ & \\
\hline Multifocal in gray matter, white matter & $9(28.1)$ & $28(18.9)$ & \\
\hline Compatible with demyelination or inflammation & $2(6.3)$ & $26(17.6)$ & \\
\hline ACA or ANA & & & 0.344 \\
\hline Positive result & $15(46.9)$ & $90(60.8)$ & \\
\hline Negative result & $15(46.9)$ & $52(35.1)$ & \\
\hline Unmeasured & $2(6.3)$ & $6(4.1)$ & \\
\hline Treatment & & & 0.000 \\
\hline No immunotherapy & $3(9.4)$ & $108(73)$ & \\
\hline Methylprednisolone & $11(34.4)$ & $23(15.5)$ & \\
\hline Immune globulin & $3(9.4)$ & $3(2.0)$ & \\
\hline Combinations of methylprednisolone and immune globulin & $14(43.8)$ & $14(9.5)$ & \\
\hline Other immunotherapy & $1(3.1)$ & 0 & \\
\hline ICU admission & $7(21.9)$ & $19(12.8)$ & 0.298 \\
\hline Coma & $5(15.6)$ & $19(12.8)$ & 0.894 \\
\hline Mechanical ventilation & $2(6.3)$ & $14(9.5)$ & 0.813 \\
\hline Outcome & & & 0.004 \\
\hline Recovered & $23(71.9)$ & $135(91.2)$ & \\
\hline Not responding to the treatment & $7(21.9)$ & $6(4.1)$ & \\
\hline Deterioration & $2(6.3)$ & $7(4.7)$ & \\
\hline
\end{tabular}

FES, focal epileptic seizure; GES, generalized epileptic seizure; ICU, intensive care unit; CSF, cerebrospinal fluid; ACA, anticardiolipin antibody; ANA, antinuclear antibody.

duration was longer than 3 months but met the other inclusion criteria described above were still included in the study to avoid missing some possible patients with clinical presentations similar to AE.
As shown in our study, among 148 patients without autoantibodies in the serum/CSF, 31 (20.9\%) patients had $\mathrm{APE}^{2}$ scores $\geq 5$. We cannot exclude the possibility that those patients diagnosed with $\mathrm{AE}$ had antibodies against intracellular antigens 
TABLE 2 | Components of the $\mathrm{APE}^{2}$ score.

\begin{tabular}{|c|c|c|c|c|c|}
\hline Components & Value (total: 18) & $\begin{array}{l}\text { Antibody- } \\
\text { positive cases } \\
\quad(n=32)\end{array}$ & $\begin{array}{l}\text { Antibody- } \\
\text { negative cases } \\
(n=148)\end{array}$ & OR (95\% CI) & $P$-value \\
\hline $\begin{array}{l}\text { 2. Neuropsychiatric changes; agitation, aggressiveness, } \\
\text { emotional lability }\end{array}$ & $(+1)$ & $26(81.3)$ & $50(33.8)$ & $5.930(2.568-13.694)$ & 0.000 \\
\hline $\begin{array}{l}\text { 4. Viral prodrome (rhinorrhea, sore throat, low grade fever) to } \\
\text { be scored in the absence of underlying systemic malignancy } \\
\text { within } 5 \text { years of neurological symptom onset }\end{array}$ & $(+2)$ & $15(46.9)$ & $20(13.5)$ & $3.655(2.030-6.582)$ & 0.000 \\
\hline 7. Seizure refractory to at least two anti-seizure medications & $(+2)$ & $17(53.1)$ & $7(4.7)$ & $7.367(4.270-12.709)$ & 0.000 \\
\hline $\begin{array}{l}\text { 8. CSF findings consistent with inflammation (elevated CSF } \\
\text { protein }>50 \mathrm{mg} / \mathrm{dl} \text { and/or lymphocytic pleocytosis }>5 \\
\text { cells } / \mu \text {, if the total number of CSF RBC is }<1,000 \text { cells } / \mu \text { l) }\end{array}$ & $(+2)$ & $21(65.6)$ & $89(60.1)$ & $1.215(0.625-2.363)$ & 0.564 \\
\hline $\begin{array}{l}\text { 9. Brain MRI suggesting encephalitis (T2/FLAIR hyperintensity } \\
\text { restricted to one or both medial temporal lobes, or multifocal } \\
\text { in gray matter, white matter, or both compatible with } \\
\text { demyelination or inflammation) }\end{array}$ & $(+2)$ & $6(18.8)$ & $21(14.2)$ & 1.308 (0.595-2.875) & 0.702 \\
\hline $\begin{array}{l}\text { 10. Systemic cancer diagnosed within } 5 \text { years of neurological } \\
\text { symptom onset (excluding cutaneous squamous cell } \\
\text { carcinoma, basal cell carcinoma, brain tumor, cancer with } \\
\text { brain metastasis) }\end{array}$ & $(+2)$ & $3(9.4)$ & $1(0.7)$ & $4.552(2.361-8.774)$ & 0.018 \\
\hline
\end{tabular}

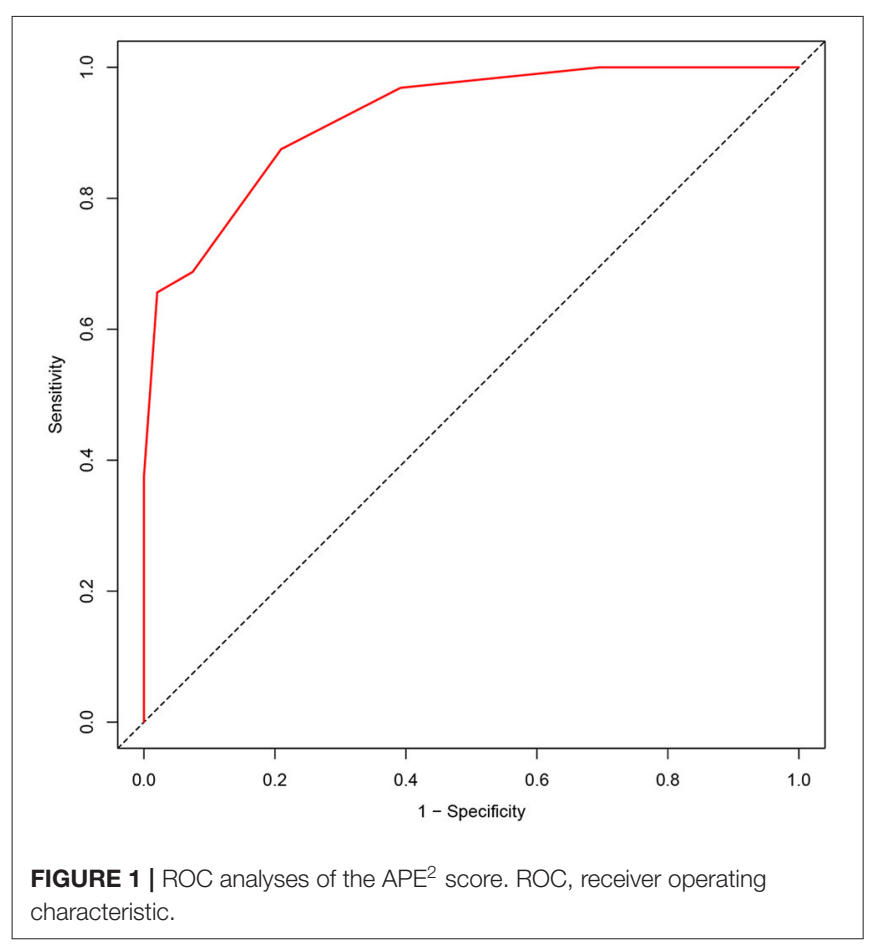

TABLE 3 | ROC and diagnostic efficiency of the $\mathrm{APE}^{2}$ score for the diagnosis of $A E$ with autoantibodies to cell-surface proteins expressed in neurons.

\begin{tabular}{lccccc}
\hline Cutoff score & Sensitivity & Specificity & PPV & NPV & YI \\
\hline 4 & 0.969 & 0.608 & 0.348 & 0.989 & 0.577 \\
5 & 0.875 & 0.791 & 0.475 & 0.967 & 0.666 \\
6 & 0.688 & 0.926 & 0.667 & 0.932 & 0.614 \\
7 & 0.656 & 0.98 & 0.875 & 0.929 & 0.636 \\
\hline
\end{tabular}

PPV, positive predictive value; NPV, negative predictive value; YI, Youden index.

or synaptic receptors. AE can be caused by the production of several different autoantibodies targeting various neuronal antigens (2). Our study focused on AE with antibodies to cell-surface proteins expressed in neurons for several reasons. First, antibodies against intracellular antigens are defined as paraneoplastic antibodies because they are frequently observed in patients with cancer (11). The most important antibodies included in this group are against $\mathrm{Ma} 2, \mathrm{Hu}$, and glutamic acid decarboxylase (GAD). AE patients with these antibodies respond significantly worse to immunosuppressive therapies than other AE patients (12). We aimed to predict the presence of antibodies to cell-surface proteins expressed in neurons based on the 


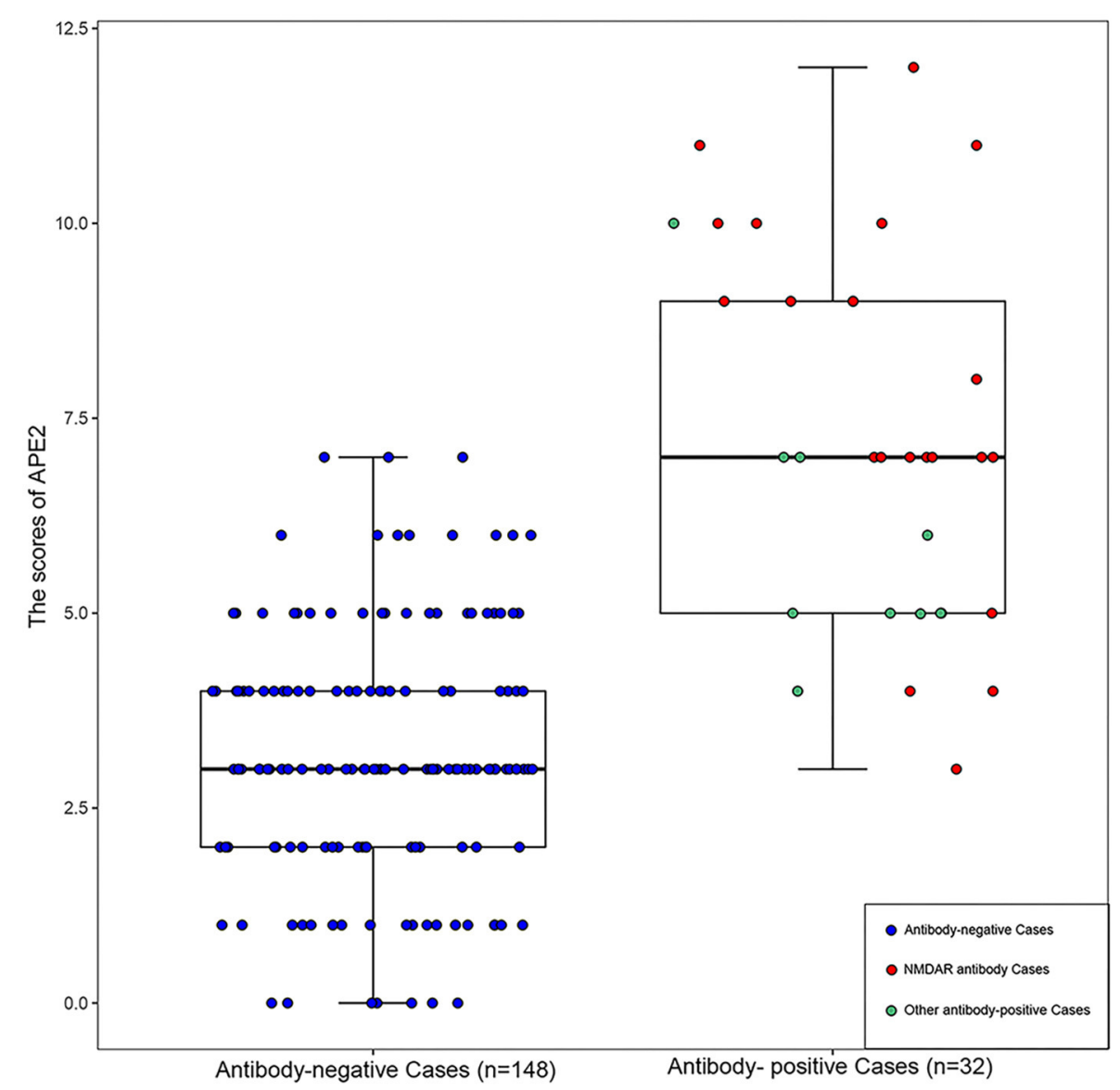

FIGURE 2 | The scores distribution of APE ${ }^{2}$ in each patient. NMDAR antibody cases: $n=23$; other antibody-positive cases including LGl1 ( $\left.n=3\right)$, GABABR $(n=3)$, CASPR2 $(n=2)$, and AMPA1 $(n=1)$.

$\mathrm{APE}^{2}$ score and to alleviate the clinical symptoms of patients through timely immunotherapy without the overutilization of these resources, which is very important in the hospital testing. On the other hand, in some areas with limited medical conditions, it is difficult to obtain early diagnosis by determining the status of antibodies. An $\mathrm{Ab}$ prediction model that is not based on Ab detection is more practical and convenient for such an applicable range. Moreover, known antibodies might only be the tip of the iceberg, and with advances in detection technology, potential new antibodies targeting the structure of neurons have been identified at an increasing rate.

It should be noted that some AE-related antibodies might be found only in the CSF $(13,14)$. An observational study showed that antibodies were found in the CSF among 250 patients with anti-NMDAR encephalitis, whereas researchers could find hardly any antibodies in the serum of $14 \%$ (36) of these patients (15). Furthermore, when the Abs found were different in the CSF and serum in one patient, although it did not occur in our study, the types of Abs in the CSF were usually determined (16). These findings supported the higher sensitivity of $\mathrm{Ab}$ testing in the CSF than in the serum. In our study, 102 patients out of 180 underwent both serum and CSF evaluations. Although 23\% of Ab-negative patients did not undergo autoantibody testing in the CSF, which could have led to false-negative results, both $\mathrm{CSF}$ and serum were used for neuronal $\mathrm{Ab}$ testing in patients in the Ab-positive group. More importantly, among 32 cases, only 2 patients had low Ab titers [NMDAR Ab, 1:10 (all CSF)]; the remaining 30 patients had high titers [range 1:16-1:1,000 (serum or CSF)]. Although the univariate analysis results found no associations between patients with only serum positivity and those with serum and/or CSF positivity $(P=0.946)$, we still recommend that both CSF and serum be used for autoantibody testing in patients with suspected AE.

Statistical analysis showed no significant differences in some items of the $\mathrm{APE}^{2}$ score. Firstly, the manifestations of the inpatients included in our study were almost mental disorders or seizures. With the exception of 24 patients with symptoms of encephalopathy for more than 1-6 weeks, the remaining $156(86.7 \%)$ patients scored 1 point on the first item. There were also no statistically significant differences in the items related to CSF inflammatory changes $(P=0.564)$ and MRI changes $(P=0.702)$. A potential reason is that Ab-negative cases included seronegative AE patients. Furthermore, 25.7\% of 
patients only checked the AE-related antibodies to cell-surface proteins expressed in neurons in the serum for this group. Therefore, patients who met the diagnostic criteria for possible $\mathrm{AE}$ should be investigated separately. It is possible that the $\mathrm{APE}^{2}$ scores might help us identify seronegative AE patients. The weighted points of these three items in the $\mathrm{APE}^{2}$ score system are 1,2 , and 2, respectively, which affects the overall scores as well as the sensitivity and specificity of the $\mathrm{APE}^{2}$ score.

Our research was based on a relatively small sample. Nevertheless, the small sample did not significantly affect the precision of the study estimates because the incidence rate of $\mathrm{AE}$ is rather low. As one of the most common forms of $\mathrm{AE}$ (17), 32 patients with anti-NMDAR encephalitis were identified among 761 cases of encephalitis with uncertain etiology in the California Encephalitis Project between September 2007 and February 2011 (18), whereas $32 \mathrm{AE}$ patients were identified among the 180 samples in our study. However, despite the usefulness of our findings, we still hope that a larger sample will be included in future studies. Furthermore, the scores and data for the model analysis for the $\mathrm{APE}^{2}$ score were derived from the analysis of a single-center retrospective study. Therefore, the data need to be interpreted with caution, and a perspective prediction with the $\mathrm{APE}^{2}$ score is needed in future studies.

\section{CONCLUSIONS}

The $\mathrm{APE}^{2}$ score was validated as a predictive model with high sensitivity and specificity for AE antibodies to cell-surface proteins expressed in neurons. Based on the evidence presented here, we suggest that patients with an $\mathrm{APE}^{2}$ score $\geq 5$ undergo $\mathrm{Ab}$ testing. The use of an objective scoring system for suspected $\mathrm{AE}$ patients as early as possible can reduce the detection cost, improve the $\mathrm{Ab}$ detection rate, and allow timely and effective treatment.

\section{REFERENCES}

1. Joubert B, Dalmau J. The role of infections in autoimmune encephalitides. Rev Neurol. (2019) 175:420-6. doi: 10.1016/j.neurol.2019.07.004

2. Graus F, Titulaer MJ, Balu R, Benseler S, Bien CG, Cellucci T, et al. A clinical approach to diagnosis of autoimmune encephalitis. Lancet Neurol. (2016) 15:391-404. doi: 10.1016/S1474-4422(15)00401-9

3. Esposito S, Principi N, Calabresi P, Rigante D. An evolving redefinition of autoimmune encephalitis. Autoimmun Rev. (2019) 18:155-63. doi: 10.1016/j.autrev.2018.08.009

4. Vincent A, Bien CG, Irani SR, Waters P. Autoantibodies associated with diseases of the CNS: new developments and future challenges. Lancet Neurol. (2011) 10:759-72. doi: 10.1016/S1474-4422(11)70096-5

5. Frank L, Tha' is A, Josep D. Autoimmune encephalopathies. Ann N Y Acad Sci. (2015) 1338:94-114. doi: 10.1111/nyas.12553

6. Zuliani L, Graus F, Giometto B, Bien C, Vincent A. Central nervous system neuronal surface antibody associated syndromes: review and guidelines for recognition. J Neurol Neurosurg Psychiatry. (2012) 83:63845. doi: 10.1136/jnnp-2011-301237

7. Dubey D, Alqallaf A, Hays R, Freeman M, Chen K, Ding K, et al. Neurological autoantibody prevalence in epilepsy of unknown etiology. JAMA Neurol. (2017) 74:397-402. doi: 10.1001/jamaneurol.2016.5429

8. Dubey D, Kothapalli N, McKeon A, Flanagan EP, Lennon VA, Klein CJ, et al. Predictors of neural-specific autoantibodies and immunotherapy response

\section{DATA AVAILABILITY STATEMENT}

The raw data supporting the conclusions of this article will be made available by the authors, without undue reservation.

\section{ETHICS STATEMENT}

The studies involving human participants were reviewed and approved by the Ethics Committee of the First Affiliated Hospital of Wenzhou Medical University. Written informed consent to participate in this study was provided by the participants' legal guardian/next of kin. Written informed consent was obtained from the individual(s), and minor(s)' legal guardian/next of kin, for the publication of any potentially identifiable images or data included in this article.

\section{AUTHOR CONTRIBUTIONS}

SD conceived the study and drafted the article. JG collected the clinical data and interpreted the data. JL and YW performed the statistical analyses, transformed the raw data into figures and tables, and compiled the references. HX contributed to the writing of successive versions of the manuscript. All authors contributed with clinical assessment, data acquisition, analysis, diagnosis, and critical revision of the article.

\section{FUNDING}

This study is supported by the Wenzhou Science and Technology Plan Project (Grant No. Y20190096).

\section{ACKNOWLEDGMENTS}

We thank all participating patients.

in patients with cognitive dysfunction. J Neuroimmunol. (2018) 323:6272. doi: 10.1016/j.jneuroim.2018.07.009

9. Dubey D, Singh J, Britton JW, Pittock SJ, Flanagan EP, Lennon VA, et al. Predictive models in the diagnosis and treatment of autoimmune epilepsy. Epilepsia. (2017) 58:1181-9. doi: 10.1111/epi.13797

10. Dubey D, Sawhney A, Greenberg B, Lowden A, Warnack W, Khemani P, et al. The spectrum of autoimmune encephalopathies. J Neuroimmunol. (2015) 287:93-7. doi: 10.1016/j.jneuroim.2015.08.014

11. Graus F, Delattre JY, Antoine JC, Dalmau J, Giometto B, Grisold $\mathrm{W}$, et al. Recommended diagnostic criteria for paraneoplastic neurological syndromes. J Neurol Neurosurg Psychiatry. (2004) 75:1135-40. doi: 10.1136/jnnp.2003.034447

12. Lladó A, Mannucci P, Carpentier AF, Paris S, Blanco Y, Saiz $\mathrm{A}$, et al. Value of $\mathrm{Hu}$ antibody determinations in the followup of paraneoplastic neurologic syndromes. Neurology. (2004) 63:1947-9. doi: 10.1212/01.WNL.0000144340.03364.BF

13. Höftberger R, van Sonderen A, Leypoldt F, Houghton D, Geschwind M, Gelfand J, et al. Encephalitis and AMPA receptor antibodies: novel findings in a case series of 22 patients. Neurology. (2015) 84:240312. doi: 10.1212/WNL.0000000000001682

14. Höftberger R, Titulaer MJ, Sabater L, Dome B, Rózsás A, Hegedus $B$, et al. Encephalitis and GABAB receptor antibodies: novel findings in a new case series of 20 patients. Neurology. (2013) 81:1500-6. doi: 10.1212/WNL.0b013e3182a9585f 
15. Gresa-Arribas N, Titulaer MJ, Torrents A, Aguilar E, McCracken L, Leypoldt F, et al. Antibody titres at diagnosis and during follow-up of anti-NMDA receptor encephalitis: a retrospective study. Lancet Neurol. (2014) 13:16777. doi: 10.1016/S1474-4422(13)70282-5

16. Petit-Pedrol M, Armangue T, Peng X, Bataller L, Cellucci T, Davis R, et al. Encephalitis with refractory seizures, status epilepticus, and antibodies to the GABAA receptor: a case series, characterisation of the antigen, and analysis of the effects of antibodies. Lancet Neurol. (2014) 13:27686. doi: 10.1016/S1474-4422(13)70299-0

17. Liu X, Yan B, Wang R, Li C, Chen C, Zhou D, et al. Seizure outcomes in patients with anti-NMDAR encephalitis: a follow-up study. Epilepsia. (2017) 58:2104-11. doi: 10.1111/epi.13929

18. Gable MS, Sheriff H, Dalmau J, Tilley DH, Glaser CA. The frequency of autoimmune N-methyl-D-aspartate receptor encephalitis surpasses that of individual viral etiologies in young individuals enrolled in the California encephalitis project. Clin Infect Dis. (2012) 54:899-904. doi: 10.1093/cid/cir1038

Conflict of Interest: The authors declare that the research was conducted in the absence of any commercial or financial relationships that could be construed as a potential conflict of interest.

Copyright (c) 2021 Ding, Gong, Lin, Wang, Hua, Li, Du, Xia, Zhu, Wang, Zheng and $\mathrm{Xu}$. This is an open-access article distributed under the terms of the Creative Commons Attribution License (CC BY). The use, distribution or reproduction in other forums is permitted, provided the original author(s) and the copyright owner(s) are credited and that the original publication in this journal is cited, in accordance with accepted academic practice. No use, distribution or reproduction is permitted which does not comply with these terms. 